\title{
WWW.PORTALFEMINISTA.ORG.BR: UMA BIBLIOTECA VIRTUAL DOS ESTUDOS FEMINISTAS E DE GÊNERO NO BRASIL
}

\author{
CLAUDIA DE LIMA COSTA \\ Universidade Federal de Santa Catarina \\ RITA MARIA XAVIER MACHADO \\ Revista Estudos Feministas
}

\begin{abstract}
Resumo: Nesse artigo fazemos uma breve exploração sobre os portais de periódicos acadêmicos e discutimos sua importância para a circulação do conhecimento. Nesse contexto, analisamos a construção de uma biblioteca virtual dos estudos feministas e de gênero. Relatamos as várias etapas do projeto Portal Feminista, tecendo reflexões sobre os desafios que cercam as publicações eletrônicas
\end{abstract}

Palovras-chave: publicações eletrônicas, biblioteca virtual, periódicos feministas.

\section{Sobre malas e bytes}

Sempre que viajava para pesquisas ou para participar de conferências e workshops, precisava dedicar quase um dia inteiro separando e selecionando papéis: os que ficariam e aqueles dos quais não poderia me separar. Feita a escolha, tinha diante de mim duas pilhas de artigos e capítulos copiados de livros, e o desafio consistia em distribuí-los pela mala, sempre consciente do peso máximo permitido pelas companhias aéreas. O último obstáculo era descer as escadas de minha casa, equilibrando-me com a mala (a qual, diga-se de passagem, não era mala de filme!). Um passo em falso e a viagem terminaria naquela escada. Essa cena se repetia monotonamente a cada viagem e, quando retornava, a mala vinha mais pesada e eu com menos dinheiro, geralmente gasto nas fotocopiadoras das bibliotecas estrangeiras e no pagamento do excesso de bagagem. Isso para não falar do tempo copiando, monotonamente, cada página dos artigos que queria trazer para o Brasil.

Hoje, a viagem ficou infinitamente simplificada. Podemos embarcar carregando somente um computador laptop ou disco rígido externo (ou ambos) e retornamos com o mesmo peso, apesar de trazermos uma quantidade imensa de artigos, todos baixados do website das bibliotecas e arquivados no disco rígido.

Gostaríamos, nesse breve artigo, de falar sobre outro tipo de deslocamento que serve de pano de fundo para a cena descrita acima: é a passagem do impresso para o digital, que veio na crista de uma longa revolução das tecnologias da informação, com 
profundas conseqüências para as publicações em geral e especialmente para os periódicos impressos. As publicações eletrônicas, ouvimos dizer, vieram para ficar. Não somos especialistas nessas novas tecnologias ou mesmo em ciência da informação uma de nós lida com teorias (literária, feminista, dos estudos culturais, etc.), e a outra com websites, mas usamos aqui o tropo da mala como uma prova material do quão mais fácil e rápido ficou a viagem dos textos (e, conseqüentemente, das teorias) pelos bytes dos computadores e bandas-largas da Internet.

Vários números do Journal of Electronic Publishing ${ }^{1}$ fazem análise minuciosa e sofisticada sobre o impacto da digitalização dos periódicos, entre outros fatores. O que gostaríamos de relatar é como, a partir dessa combustão digital, pensamos e propomos a construção de um portal de periódicos feministas acadêmicos no Brasil, liderado pela Revista Estudos Feministas e com apoio da Fundação Ford e da Universidade Federal de Santa Catarina.

\section{A era da versão eletrônica dos periódicos}

O antropólogo indiano Arjun Appadurai, em seu conhecido livro sobre os processos e movimentos causados pela globalização, identifica cinco dimensões dos fluxos na pósmodernidade, denominados, respectivamente, de etnopanoramas, tecnopanoramas, finançopanoramas, midiapanoramas, e ideopanoramas. ${ }^{2}$ A 'virada' digital, concomitantemente com o crescimento e expansão da Internet, vêm possibilitando uma grande velocidade nos fluxos de informação, imagens e símbolos que compõem os midiapanoramas. Segundo esse autor,

midiapanoramas se referem à distribuição de suportes eletrônicos capazes de produzir e disseminar informação (jornais, revistas, canais de televisão, e estúdios cinematográficos), disponível para um número progressivo de interesses públicos e privados ao redor do mundo, bem como as imagens do mundo criadas por essa mídia. ${ }^{3}$

No rastro dos mediapanoramas, assistimos ao surgimento da "era das bibliotecas sem paredes para livros sem páginas". ${ }^{4}$ Com espaços físicos cada vez mais reduzidos, as bibliotecas institucionais (e mesmo as particulares - aquelas que temos em casa e usamos para instrumentalizar nossas/os alunos/as) têm ultimamente optado pela assinatura de grandes portais de periódicos eletrônicos devido à facilidade de acesso. Esses portais podem variar segundo critérios para inclusão (alguns muito rígidos, como é o caso do ISI Web of Science e Current Contents ) ou dependendo do enfoque por área disciplinar (ciências exatas, literatura, ciências sociais, etc) e/ou especificidades temáticas. Há, nesse leque de bancos de dados das bibliotecas estrangeiras, principalmente as norteamericanas, aqueles que veiculam as publicações sobre feminismo, teorias feministas e estudos de gênero. Somente para dar um exemplo, a biblioteca digital da Universidade de Califórnia permite atualmente acesso a um total de 20.231 periódicos acadêmicos eletrônicos com textos completos. ${ }^{5}$ A maioria desses periódicos se encontra em portais ou bancos de dados reunindo publicações por áreas temáticas. Retornando ao exemplo anterior, na Universidade de Califórnia os bancos de dados especializados encontram-se divididos em quatro grandes áreas: Artes (36 portais), Humanidades (1 14), Ciências Sociais (125), Ciências e Engenharias (143). ${ }^{6}$ Essas grandes áreas se subdividem em uma variedade de temas. Em relação aos estudos feministas e de gênero, e dentre os vários bancos de dados existentes, podemos citar o GenderWatch (banco de dados com artigos completos de periódicos acadêmicos, revistas, jornais, boletins, anais de congressos e documentos oficiais enfocando o impacto que o gênero nas disciplinas), o Contemporary Women's 
Issues (com artigos completos de periódicos acadêmicos, boletins e relatórios nas áreas da sociologia, psicologia, saúde, educação e direitos humanos) e, a guisa de curiosidade, o North-American Women's Letters and Diaries (com os textos completos dos diários e cartas das mulheres norte-americanas da época colonial até 1950).

No Brasil e na América Latina, ao contrário dos países do Norte e diante da escassez de recursos que assolam as universidades e instituições científicas, a existência de tais portais com os textos integrais dos periódicos é consideravelmente mais limitada. Podemos citar aqui novamente o portal Scientific Electronic Library Online (SciELO), ${ }^{7}$ cuja área de abrangência cobre periódicos científicos latino-americanos; a Red de Revistas Cientificas de América Latina y El Caribe, España y Portugal (Red Alyc); ${ }^{8}$ o Projeto P@piro de Publicações Digitais da Universidade Central de Venezuela; ${ }^{9}$ e, no Brasil, o Portal Brasileiro de Informação Científica, já mencionado anteriormente.

No espaço latino-americano, quando entramos na área dos estudos feministas e de gênero não encontramos a mesma iniciativa que já desponta em relação aos outros campos do saber. ${ }^{10} \mathrm{Com}$ o intuito de preencher essa lacuna, decidimos então criar um portal que reunisse publicações acadêmicas brasileiras especializadas sobre estudos feministas e de gênero, disponibilizando o acesso aos seus textos integrais.

\section{O Portal Feminista}

Uma pesquisa realizada em 2001 pela Associação Brasileira de Celulose e Papel, Câmara Brasileira do Livro e Sindicato Nacional dos Editores de Livros revelou estatísticas bastante inquietantes sobre o retrato da leitura no Brasil. Segundo os dados levantados, temos o seguinte quadro em relação ao acesso dos/as brasileiros/as a livros e bibliotecas: ${ }^{11}$

Estudos do Ministério da Cultura indicam que cerca de 1.300 municípios brasileiros das regiões mais pobres não possuem uma biblioteca pública.

- Metade dos livros lidos atualmente não são comprados.

$61 \%$ dos brasileiros adultos alfabetizados têm muito pouco ou nenhum contato com os livros.

6,5 milhões de pessoas das camadas mais pobres da população dizem não ter nenhuma condição de adquirir um livro.

- De cada 10 não-leitores, 7 têm baixo poder aquisitivo.

$73 \%$ dos livros estão concentrados nas mãos de apenas $16 \%$ da população.

Mais da metade dos compradores de livros (58\%) concentram-se em seis estados das regiões sul e sudeste.

Sobre o mercado de livros, as estatísticas são as seguintes:

- O Brasil possui 1.500 livrarias (o ideal seria existirem 10 mil).

- $89 \%$ dos municípios brasileiros não possuem livrarias.

- $O$ mercado editorial brasileiro está em oitavo lugar em volume de produção no ranking mundial.

Existem cerca de 530 editoras ativas, ou seja, que publicaram ao menos cinco livros em um ano ou com tiragem acima de 10 mil exemplares.

- Nos Estados Unidos, $30 \%$ dos livros editados são adquiridos pelos acervos públicos. No Brasil, somente $1 \%$ da produção editorial destina-se às bibliotecas.

A aquisição de livros pelas bibliotecas norte-americanas é maior do que todo o consumo brasileiro.

Tendo como pano de fundo os exemplos dos bancos de dados acima citados, e diante da necessidade premente de possibilitar maior circulação e alcance do conhecimento sobre os estudos feministas e de gênero, decidimos criar um banco de 
dados que disponibilizasse eletronicamente os textos completos dos periódicos acadêmicos brasileiros sobre os estudos feministas e de gênero, numa primeira fase e, em etapa posterior, conhecimentos alternativos na mesma área gerados por diferentes sujeitos situados em outros lugares de enunciação além da academia (Ongs, centros de pesquisa, instituições governamentais, movimentos sociais e comunidades, etc.).

Escolhemos um banco de dados específico, o Project Muse,,$^{12}$ como modelo de metodologia para o Portal Feminista, adaptando-o para a nossa realidade marcada por recursos infinitamente mais limitados. Diante da pergunta "por que um portal de publicações eletrônicas?" e fazendo uma consulta aos debates publicados em vários números do Journal of Electronic Publishing, elaboramos uma relação das vantagens e desvantagens das publicações eletrônicas:

Vantagens:

- Acesso - possibilitam maior acesso através da Internet, resolvendo os problemas de distribuição que tanto assolam as publicações no Brasil e limitam a difusão do conhecimento (segundo pesquisa comparativa feita sobre o público leitor, no Brasil há uma livraria para cada 84,400 habitantes, enquanto que na Argentina, por exemplo, há uma livraria para cada 6.200 habitantes). ${ }^{13}$

- Igualdade (relativa) de acesso - tanto pesquisadoras/es em instituições com mais recursos quanto pesquisadoras/es em instituições com recursos limitados têm a mesma oportunidade de acesso. Para isso basta ter um computador (com possibilidade de navegação na Internet) ligado a um provedor, coisa que muitas instituições de ensino e pesquisa, bem como ONGs, já possuem.

Velocidade - a versão eletrônica da revista pode ser disponibilizada antes mesmo de sua versão impressa, permitindo assim acesso imediato aos artigos publicados e, portanto, uma disseminação mais rápida do conhecimento.

Impacto - os artigos que estiverem mais rapidamente acessíveis terão um maior impacto; a versão eletrônica também possibilita o registro do número de vezes que um determinado artigo foi consultado, tornando mais visível seu impacto.

Facilidade de consulta - a versão eletrônica do periódico permite que consultas sejam feitas de qualquer lugar.

- Facilidade de arquivamento - as versões eletrônicas dos periódicos não têm o problema dos números esgotados. O acesso aos artigos em números impressos esgotados é sempre garantido.

Facilidade de busca - a versão eletrônica permite maior facilidade para pesquisa (a partir de palavras-chave, autoras, temas, etc.) tanto de revistas avulsas como das revistas incluídas na biblioteca virtual.

- Facilidade para venda e controle de assinaturas - cada revista terá seu formulário para pedidos de assinaturas, que poderão ser feitas online. Isso possibilitará um maior controle das assinaturas através do arquivamento das mesmas no sistema e a partir da distribuição de login e senha.

Baixo custo - depois de montada a infra-estrutura tecnológica básica, disponibilizar a versão eletrônica em arquivos HTML ou PDF não implica em operações complicadas nem de alto custo.

Garantia de existência - caso não haja mais recurso para continuar a versão impressa do periódico, este pode passar facilmente a existir unicamente em sua versão online, já que seus custos são significativamente menores e sua produção mais ágil e flexível.

Possibilidade de produção dos números do periódico em CD-ROM. 
Entre as desvantagens, identificamos na nossa pesquisa as seguintes preocupações: - Acesso restrito a tecnologias de comunicação e a computadores com capacidade de navegação na Internet;

Dificuldade de leitura dos textos online (a resolução dos monitores ainda não conseguiu reproduzir a textura da página impressa); $;^{14}$

Anotação - podem-se anotar observações mais facilmente em uma página impressa do que em um texto eletrônico;

Dificuldade de transporte de tais textos (pode-se carregar e manusear mais facilmente um periódico impresso do que um eletrônico).

Tendo em vista que as vantagens em muito superavam as desvantagens, portanto fomos adiante com a proposta do Portal Feminista, decidindo também aproveitar a sua infra-estrutura de hardware e software para implementar outras seções: interessado.

Seção de teses - Incluirá um formulário para preenchimento pelo próprio

Seção de enquetes - Permitirá consultas aos usuários do Portal

Seção de eventos, palestras, encontros, etc. - Possibilitará que pessoas ou entidades interessadas cadastrem seus eventos nos formulários específicos.

Entre idealizar e implementar uma biblioteca virtual há uma enorme distância epistemológica e metodológica - principalmente quando não tínhamos treinamento específico sobre tecnologias de informação e o 'mundo virtual.' A materialização desse projeto tão inovador na área dos estudos feministas e de gênero no Brasil e na América Latina exigiu um longo aprendizado de nossa parte, cheio de percalços e palpitações, mas também pontuado por muitas satisfações. Passaremos agora a um relato dessas etapas, menos gloriosas e mais desafiadoras, do projeto.

\section{Portal Feminista: a fase da instalação}

Imaginar um portal na Internet é, obviamente, muito mais fácil do que concretizálo. O mundo das idéias não comporta limites; entretanto, no mundo 'real' (e 'virtual') estes aparecem assim que tentamos colocar qualquer empreendimento em funcionamento. Com o Portal Feminista não foi diferente.

Após o recebimento dos recursos, partimos para a escolha dos equipamentos e programas de software necessários, tais como servidor, computador, softwares, empresas fornecedoras, entre outras exigências. Isso feito, a etapa seguinte foi gerenciar as equipes designadas para desenvolver cada segmento do portal (duas no Rio de Janeiro e uma em Florianópolis) e, enquanto isso, ainda aprender a administrar o próprio portal pela primeira vez. ${ }^{15}$ Curiosamente, uma das dificuldades que tivemos e se apresentou logo no início foi dar um nome ao portal para que pudéssemos registrar o domínio.

O primeiro nome escolhido, Tessituras, foi rejeitado por ampla maioria em animadíssima reunião de editoras/es de publicações feministas ocorrida durante o I Encontro Nacional de Publicações Feministas. ${ }^{16}$ Por conta dessa mesma animação, tivemos uma proliferação de sugestões (entre elas, a de Medéia, Macabéa, e assim por diante) e muitas risadas, mas, infelizmente, nenhum consenso. A solução foi deixarmos a escolha do nome definitivo para o futuro: este seria selecionado em uma enquete promovida através do próprio portal.

Registramos o domínio como Portal Feminista e seguimos adiante com o projeto.

Quase um ano mais tarde, depois de listas e listas de especificações, o software e o banco de dados foram instalados no servidor, hospedado na Universidade Federal de 
Santa Catarina. Passamos então para a fase dos testes do software Gutemberg, desenvolvido e customizado pela Winco Tecnologia e Sistemas, o qual administra o conteúdo do Portal. Alguns meses e várias correções depois, os primeiros números da versão eletrônica da Revista Estudos Feministas apareceram em formato eletrônico no Portal Feminista. Desde então, vivemos numa espécie de montanha-russa, alternando grandes alegrias, novas dificuldades e algumas frustrações.

\section{Algumas surpresas}

Desde o início deste projeto, tivemos em mente a intenção de disponibilizarmos, em versão eletrônica, os números esgotados da Revista Estudos Feministas e das diversas publicações que futuramente se integrassem ao Portal Feminista. Qual não foi a nossa surpresa quando percebemos que, por mais que tentássemos e mesmo com os recursos de software que dispúnhamos, tal não seria possível. Tivemos então que investir recentemente em mais um equipamento - um scanner de alta capacidade, com software adequado para gerar arquivos em PDF, próprios para veiculação eletrônica a partir da versão em papel dos periódicos. Com isso, começamos a publicar no Portal Feminista a versão eletrônica dos primeiros números da Revista Estudos Feministas que se encontram esgotados em sua versão impressa.

Também registramos com alegria a chegada, neste mesmo mês, do material da revista Gênero, cujos artigos aparecerão em breve na versão eletrônica no Portal Feminista. Aguardamos, também para um futuro próximo, a disponibilização dos Cadernos Pagu e de outras publicações que estarão recebendo nossa chamada.

Aprendemos, ao longo desse percurso, que as dificuldades e os problemas nunca desaparecerão. Compreendemos que o meio virtual é leve, rápido, de fácil acesso e, mais do que tudo, imprevisível. Porém, não devemos nem podemos deixá-lo de lado. Nos sentimos agora preparadas para administrar as dificuldades, porque sabemos que elas continuarão aparecendo, mas que não irão ofuscar o prazer que temos quando vemos concretizada aquela idéia original de um banco de dados de publicações feministas brasileiras na Internet.

Enquanto preparávamos esse breve relato da construção do Portal Feminista, tomamos conhecimento de uma importante notícia sobre o Google, a qual enfatiza a relevância das publicações eletrônicas. Gostaríamos de encerrar nossa breve reflexão com o texto dessa notícia, veiculado no jornal O Estado de São Paulo online:

O Google anunciou hoje que irá criar cópias digitalizadas de milhões de livros de grandes bibliotecas, entre as quais as das universidades de Michigan, Oxford, e a de Nova York, de modo que eles possam ser localizados por meio de seu sistema de buscas e lidos online. As páginas com os resultados dos livros escaneados não terão anúncios mas conterão links que levarão ao site da Amazon.com. "O objetivo é trazer a enorme gama de informação que está no papel e disponibilizá-la para os internautas", disse Susan Wojcicki, gerente de produto do Google ao CnetNews. A tarefa proposta pelo Google é gigantesca: somente para digitalizar a coleção completa de Michigan - sete milhões de volumes serão necessários cinco anos. Segundo Paul LeClerc, presidente da Biblioteca Pública de Nova York, o projeto resolverá um antigo problema: "Se, por várias razões, incluindo a distância, as pessoas não podem vir até nós, agora nós iremos a elas", ele comentou. ${ }^{17}$

\section{Notas}

Copyright (C) 2004 by Revista Estudos Feministas.

${ }^{1}$ http://www.press.umich.edu/jep/ 


\begin{abstract}
${ }^{2}$ APPADURAI, 1996
${ }^{3}$ APPADURAI, op. cit., p. 35 (tradução de Claudia de Lima Costa).

${ }^{4}$ BROWNING, 2002 (citado em Miriam Vieira CUNHA, 2004).

${ }^{5}$ Apesar da iniciativa inovadora e meritória da CAPES na criação do Portal Brasileiro de Informação Científica (www. periodicos.capes.gov.br), há apenas em torno de 8.453 periódicos internacionais e nacionais com textos completos disponibilizados para pesquisadores/as no Brasil, em marcante contraste com os recursos oferecidos pelas universidades norte-americanas. Não podemos deixar de mencionar também o portal SciELO (www.scielo.com.br), que se tornou no Brasil e na América Latina uma referência para as publicações acadêmicas.

${ }^{\circ}$ Os bancos de dados mais populares são Infotrac Expanded Academic, LexisNexis Academic, Web of Science e Current Contents.

${ }^{7}$ http:// www.scielo.com.br

${ }^{8} \mathrm{http}: / /$ redalyc.uaemex.mx/

${ }^{9}$ www.revele.com.ve

${ }^{10} \mathrm{~A}$ importante base de dados brasileira Prossiga (www.prossiga.com.br) possuiu várias bibliotecas virtuais temáticas, incluindo a Biblioteca Virtual Mulher (http://www.prossiga.br/bvmulher/cedim/), com documentos, dados, informações e links para outras bibliotecas virtuais ou mesmo periódicos. Porém, elas não podem ser classificadas como portais de periódicos, pois alguns dos links somente nos levam às páginas principais desses periódicos, ou seja, não permitem necessariamente acesso aos seus textos integrais. Podemos dizer o mesmo em relação à base de dados sobre relações de gênero da Fundação Carlos Chagas, particularmente o Programa de Dotações para Pesquisa sobre Mulheres e Relações de Gênero (http:// www.fcc.org.br/pesquisa/projetos.html), cuja base de dados apresenta o acervo de todos os projetos aprovados nos oito concursos de pesquisa do Programa de Dotações, além de permitir consulta online ao tesauro para estudos de gênero e sobre mulheres.

"Esses dados estão disponíveis no site http://www.radiobras.gov.br/materia.phtml?materia=187985\&q=1 \&editoria= acessado em 19 de dezembro de 2004.

${ }^{12} \mathrm{http}: / /$ muse.jhu.edu/

${ }^{13}$ Veja nota no. 7.

${ }^{14}$ Vale observar aqui que as pesquisas sobre papel digital se encontram bastante desenvolvidas. Segundo o BBC News, Sony, Philips e a companhia E-Ink já desenvolveram um leitor para livros eletrônicos, o Librié, do tamanho de um livro de bolso e com capacidade para armazenar até 500 textos. Com ótima resolução (170 pixels por polegada), o Librié pode ser lido facilmente de todos os ângulos e até sob a luz do sol. As baterias do Librié permitem a leitura de até 10 mil páginas entre cada recarga ( http://news.bbc.co.uk/1/hi/ technology/3568505.stm, acessado em 30 de dezembro de 2004).

${ }^{15}$ Gostaríamos de agradecer a consultoria de Carla Rodrigues no referente a busca de um software que atendesse as especificidades do Portal Feminista.

${ }^{16}$ Neste encontro foi divulgada ao público pela primeira vez a informação sobre o portal feminista e um convite foi feito às/aos participantes para que integrassem suas publicações a ele.

${ }^{17} \mathrm{http}: / /$ wwwl $1 . e s t a d a o . c o m . b r / t e c n o l o g i a / i n t e r n e t / 2004 / d e z / 14 / 27 . h t m$, acessado em 19 de dezembro de 2004.
\end{abstract}

\title{
Referências
}

APPADURAI, Arjun. Modernity at Large: Cultural Dimensions of Globalization. Minneapolis: University of Minnesota Press, 1996.

CUNHA, Miriam Vieira. "O papel social do bibliotecário". http://www.encontros-bibli.ufsc.br/ Edicao_15/cunha_papel social.pdf, acessado em 29 de novembro de 2004.

www.portalfeminista.org.br: Brazilian Feminist and Gender Studies Virtual Library

Abstract: This article provides a brief foray into the world of academic journal databanks and its importance for the circulation of knowledge. In this context, we discuss the need to construct a databank in the area of feminist and gender studies. We explain the different stages in the construction of the Portal Feminista, reflecting on the challenges of electronic publications. Keywords: electronic publishing, virtual library, feminist journals 